\title{
Therapeutic Use of Exercising in Hypoxia: Promises and Limitations
}

\author{
Gregoire P. Millet ${ }^{1 *}$, Tadej Debevec ${ }^{2}$, Franck Brocherie ${ }^{1}$, Davide Malatesta ${ }^{1}$ and \\ Olivier Girard ${ }^{1}$
}

${ }^{1}$ Institute of Sport Sciences of the University of Lausanne (ISSUL), Lausanne, Switzerland, ${ }^{2}$ Department of Automation, Biocybernetics and Robotics, Jožef Stefan Institute, Ljubljana, Slovenia

Keywords: hypoxia-inducible factor 1, alpha subunit, hypoxia, brain, obesity, hypertension, elderly

It is well-established that different altitude training modalities can improve convective oxygen $\left(\mathrm{O}_{2}\right)$ transport capacity and physical fitness of athletes (Millet et al., 2010). Exercising in hypoxia also induces specific muscular adaptations including increased oxidative enzymes (e.g., citrate synthase) activity, mitochondrial density, capillary-to-fiber ratio, and fiber cross-sectional area (Hoppeler et al., 2008). These changes with hypoxic training are mostly modulated via hypoxia-inducible factor $1 \alpha(H I F-1 \alpha)$ signaling cascade, which is not activated to the same extent when training is performed in normoxia or by passive hypoxic exposure. Indeed, large body of literature shows that, compared to hypoxic exercise, passive exposure to hypoxia does not provoke similar acute responses. In healthy individuals, both systemic (e.g., performance enhancement), cardiovascular (e.g., maximal $\mathrm{O}_{2}$ uptake, $\mathrm{VO}_{2 \max }$ ) or transcriptional muscular responses are minimal with intermittent passive exposures at moderate altitude. On the other hand, there are clear evidences that when hypoxia is combined with exercise, it triggers specific responses, not observed following similar exercise in normoxia (Bartsch et al., 2008; Lundby et al., 2009). In addition, greater specific adaptations have been reported in high-intensity vs. moderate-intensity hypoxic intervention (Faiss et al., 2013) (e.g., improvements in muscle $\mathrm{O}_{2}$ homeostasis and tissue perfusion induced by enhanced mitochondrial efficiency, control of mitochondrial respiration, angiogenesis, and muscle buffering capacity). It seems that the main underlying mechanism is the larger hypoxemia resulting from the combination of muscle deoxygenation (high-intensity exercise) and systemic desaturation (moderate hypoxia).

In patients or elderly individuals, altitude is generally associated with increased health risks through enhanced sympathetic vasoconstrictor activation (Blitzer et al., 1996), obstructive sleep apneas (Nespoulet et al., 2012), hypoxemia (Levine et al., 1997), pulmonary hypertension (ValenciaFlores et al., 2004), arrhythmias (Kujanik et al., 2000), and alterations of postural control (Degache et al., 2012). However, several studies have investigated the therapeutic benefits of exercising in mild hypoxia on the blood pressure regulation and the influence of different hypoxic modalities in healthy individuals (Bailey et al., 2001; Wang et al., 2007; Haufe et al., 2008; Nishiwaki et al., 2011; Morishima et al., 2014; Shi et al., 2014) or in patients with different cardiovascular and respiratory risk factors such as chronic obstructive pulmonary disease (COPD) (Haider et al., 2009), obesity (Wiesner et al., 2010), coronary artery disease (Burtscher et al., 2004). Recent studies (Haufe et al., 2008; Wiesner et al., 2010) have also reported that sustained hypoxia may be of benefit to weight management programs of obese patients (Urdampilleta et al., 2012; Kayser and Verges, 2013). Both exercise (Williams et al., 2002) and/or intermittent hypoxia (Burtscher et al., 2004; Shatilo et al., 2008) have been suggested to positively influence age-related alterations in elderly individuals. Finally, living at altitude seems to have contradictory effects on different mortality risk factors.

Therefore, this essay summarizes recent evidences suggesting that exercising in hypoxia might be a valuable and viable "therapeutic strategy." We discuss the benefits and risks/limitations in (i) hypertensive (ii) obese, (iii) elderly individuals. Since the benefits of being active have been extensively investigated in these three groups of individuals (see respective reviews on the effects of physical activity in Cherubini et al., 1998; Baillot et al., 2014; Borjesson et al., 2016), the present article focus on the potential additional health benefits 
provided by hypoxic exercise, when compared to normoxic exercise. For safety and practical reasons, patients cannot access high altitude (even by using hypoxic devices) and preferably stay at moderate altitude (1800-3000 m). In this setting, exercise is used to increase the overall hypoxia-induced metabolic stress and thereby provide benefits beyond those achievable by normoxic therapeutic training modalities.

\section{HYPERTENSION}

Systemic hypoxia (i.e., reduction in the $\mathrm{O}_{2}$ arterial content) at rest elicits acute vasodilation in conduit arteries [reduction in arterial stiffness (Vedam et al., 2009)] and augments blood flow within the skeletal muscle vascular beds, which occurs despite an enhanced sympathetic vasoconstrictor activity. There are direct evidences that during hypoxic exposure endothelium-derived nitric oxide (NO)-mediated mechanisms are largely involved in the vasodilatation of muscular arteries (but not the aorta; Vedam et al., 2009). Leuenberger et al. (2008) further showed that hypobaric hypoxia is associated with increased $\mathrm{NO}$ in venous effluent from skeletal muscle but not in the skeletal muscle interstitium.

Systemic hypoxia per se leads to peripheral vasodilation that aims to counteract the decrease in $\mathrm{O}_{2}$ content and subsequent peripheral $\mathrm{O}_{2}$ delivery. In former Soviet Union countries, intermittent hypoxic exposure at rest (Bernardi et al., 2001) was applied therapeutically to lower blood pressure in hypertensive patients with numerous positive reports (Serebrovskaya et al., 2008). Skeletal muscle vasodilation associated with hypoxia is due to release of vasodilator substances of which the $\mathrm{NO} / \mathrm{NO}$ synthase pathway seems to play a central role. However, there is a synergistic effect of hypoxic and exercise stressors on the magnitude of this response. When physical exercise is added to the hypoxic exposure, blood flow increases to contracting muscles that compensate for the reduced arterial $\mathrm{O}_{2}$ content and keeps $\mathrm{O}_{2}$ delivery to the active muscle relatively constant; a phenomenon called "compensatory vasodilatation" (Casey and Joyner, 2011). Although, a number of other vasoactive substances are also produced by the endothelium in an $\mathrm{O}_{2}$-sensitive manner [i.e., adenosine (Leuenberger et al., 1999); prostaglandins (Messina et al., 1992)], NO appears to be the major contributor to the compensatory vasodilator responses. Hypoxia and physical exercise are independent and highly potent metabolic stressors (Bailey et al., 2001). Acute hypoxic exposure reduces arterial $\mathrm{O}_{2}$ saturation level, whereas physical exercise increases $\mathrm{VO}_{2 \max }$ by working muscles (Wang et al., 2010). Hence, hypoxic exercise considerably reduces the $\mathrm{O}_{2}$ partial pressure within the mitochondria of the working organs by simultaneously decreasing $\mathrm{O}_{2}$ supply and increasing $\mathrm{O}_{2}$ demand (Wang et al., 2010). Owing to hypoxia-induced augmentation of exercise hypoxemia, the reduction of blood pressure by "compensatory vasodilatation" mechanisms may be larger than that by exercise alone. In particular, compared to similar training at sea level, moderate-intensity hypoxic training was shown to be superior for improving aerobic capacity and increasing the production of various circulating progenitor cells subsets and angiogenic factors, associated with enhanced hemodynamic responses to exercise in sedentary individuals (i.e., vasodilation in coronary and resistance vessels by increased NO production, vascular endothelial growth factor (VEGF) production; Wang et al., 2007). Similarly, exercise training under mild intermittent hypoxic conditions ( $2000 \mathrm{~m}$ simulated altitude) seems to be more efficient in reducing arterial stiffness and inducing vascular functional adaptation in the form of an increased flow mediated dilation (FMD) response amplitude compared to similar normoxic training (Nishiwaki et al., 2011). Taken together the above evidences suggest that adding hypoxic stimuli to exercise induces greater reductions in blood pressure, compared to normoxic training and enhances various aspects of the vascular function, which are pertinent for the reduction of cardiovascular risks.

\section{OBESITY}

Obesity is characterized by an increased mass of adipose tissue (excessive fat accumulation) resulting from a systemic imbalance between food intake and energy expenditure (i.e., positive energy balance). Beside obesity-related disorders, the visceral adiposity impairs endothelial function and increases the vascular media thickness and arterial stiffness (Weil et al., 2011). Obese individuals often present chronic inflammation of the adipose tissue, which is considered to play an important role in the initiation and development of obesity-related comorbidities, and increases of the oxidative stress within the fat tissue. Hypoxia seems to be involved in the inflammationrelated within the poorly oxygenated adipose tissue (e.g., secretion of several adipokines affecting endothelial function and promoting a systemic inflammatory state). Thus, systemic and local inflammation associated with oxidative stress, adipokine dysregulation and increased sympathetic nervous actions is implicated in endothelial dysfunction in obesity.

Pioneering studies (Haufe et al., 2008; Wiesner et al., 2010) have reported that, despite lower training workload and therefore lower mechanical strain in hypoxia, this environmental condition may lead to significant weight loss and improve metabolic and cardiorespiratory health, leading to suggestions that sustained hypoxia may be of benefit to weight management programs of obese patients (Urdampilleta et al., 2012; Kayser and Verges, 2013). This phenomenon is also known as "altitude anorexia" and is underlined by decreased food intake and hypoxiainduced appetite reduction, as a consequence of increases in the appetite reducing and satiety signaling peptides leptin or cholecystokinin, concomitant with a reduction in the hungerstimulating hormone ghrelin (Yingzhong et al., 2006). In addition, hypoxia exposure also seems to result in increased energy expenditure (Kayser and Verges, 2013). In line with the above, higher altitude of residence was recently shown to be associated to lower obesity rates (Voss et al., 2014).

\section{AGING}

Aging is associated with a progressive increase in systolic blood pressure and development of arterial hypertension (via atherosclerotic changes, stiffening of arteries, altered renal function, and arterial baroreflex impairment), leading to 
increased risk for cardiovascular or coronary heart diseases (Levy et al., 1996). Moreover, sarcopenia (muscle loss) is accompanying aging (Janssen et al., 2002), mainly due to a decrease in fast-twitch fiber cross-sectional area (Verdijk et al., 2007). This phenomenon may be masked by fat mass accumulation (Gallagher et al., 2000), which also reduces vascularization and angiogenic capacity and increases the risk of cardio-metabolic disorders. Overall, these degenerative-dystrophic alterations predispose tissue to local hypoxia (Lenaz et al., 2002; Sharma and Goodwin, 2006). However, altitude residence' effect appears controversial. For instance, it may detrimentally affect certain lung conditions such as chronic COPD (Cote et al., 1993) or pneumonia (PerezPadilla and Franco-Marina, 2004). On the other hand, certain cardiovascular risks seem to be reduced with living in altitude. In particular lower ischemic heart disease risk (Faeh et al., 2009, 2016) and reduction in mortality from coronary heart disease (Mortimer et al., 1977) or dialysis (Winkelmayer et al., 2009; Shapiro et al., 2014) have been reported in high altitude patients. Improved myocardial angiogenesis or ventricular remodeling have been proposed as the main underlying mechanisms (Sasaki et al., 2002).

While caution may be requested regarding the utilization of hypoxic training with elderly individuals, passive intermittent hypoxic exposure was shown to increase exercise tolerance and $\mathrm{VO}_{2 \max }$ (Burtscher et al., 2004). Furthermore, healthy elderly individuals well-tolerated intermittent hypoxic training, with greater effect on haemodynamic, microvascular endothelial function, and work capacity in untrained participants (Shatilo et al., 2008). Recently, resistance training under systemic hypoxia

\section{REFERENCES}

Bailey, D. M., Davies, B., and Young, I. S. (2001). Intermittent hypoxic training: implications for lipid peroxidation induced by acute normoxic exercise in active men. Clin. Sci. (Lond). 101, 465-475.

Baillot, A., Audet, M., Baillargeon, J. P., Dionne, I. J., Valiquette, L., Rosa-Fortin, M. M., et al. (2014). Impact of physical activity and fitness in class II and III obese individuals: a systematic review. Obes Rev. 15, 721-739. doi: 10.1111/obr.12171

Bärtsch, P., Dehnert, C., Friedmann-Bette, B., and Tadibi, V. (2008). Intermittent hypoxia at rest for improvement of athletic performance. Scand. J. Med. Sci. Sports 18(Suppl. 1), 50-56. doi: 10.1111/j.1600-0838.2008.00832.x

Bernardi, L., Passino, C., Serebrovskaya, Z., Serebrovskaya, T., and Appenzeller, O. (2001). Respiratory and cardiovascular adaptations to progressive hypoxia; effect of interval hypoxic training. Eur. Heart J. 22, 879-886. doi: 10.1053/euhj.2000.2466

Blitzer, M. L., Loh, E., Roddy, M. A., Stamler, J. S., and Creager, M. A. (1996). Endothelium-derived nitric oxide regulates systemic and pulmonary vascular resistance during acute hypoxia in humans. J. Am. Coll. Cardiol. 28, 591-596.

Börjesson, M., Onerup, A., Lundqvist, S., and Dahlöf, B. (2016). Physical activity and exercise lower blood pressure in individuals with hypertension: narrative review of 27 RCTs. Br. J. Sports Med. 50, 356-361. doi: 10.1136/bjsports-2015095786

Burtscher, M., Pachinger, O., Ehrenbourg, I., Mitterbauer, G., Faulhaber, M., Pühringer, R., et al. (2004). Intermittent hypoxia increases exercise tolerance in elderly men with and without coronary artery disease. Int. J. Cardiol. 96, 247-254. doi: 10.1016/j.ijcard.2003.07.021

Casey, D. P., and Joyner, M. J. (2011). Local control of skeletal muscle blood flow during exercise: influence of available oxygen. J. Appl. Physiol. 111, 1527-1538. doi: 10.1152/japplphysiol.00895.2011

Cherubini, A., Donahue, J. L., Lowenthal, D. T., Mecocci, P., Meuleman, J. R., Maggio, D., et al. (1998). The effects of aging and endurance exercise on was shown to result in greater muscle size and strength and endurance increases as well as angiogenesis in the skeletal muscles (Kon et al., 2014). Taken together, these findings suggest that combining exercise, be it low- to-high-intensity aerobic or resistance, with hypoxic stressor would play a role in slowing sarcopenia development as well as improving physical capacity (via hypotensive and antioxidant actions) and well-being of elderly individuals.

Logically, the next question is: what is the optimal combination of exercise and hypoxia?

Hypoxia and exercise may have synergistic (positive) effects in hypertensive, obese or elderly subjects. However, little is known regarding the optimal combination between the physical activity (e.g., exercise intensity, type of activity) and hypoxic (e.g., altitude level, optimal hypoxic dose, normobaric vs. hypobaric hypoxia) components. Different combinations of these two factors have to be further investigated to identify optimal and individually tailored hypoxic exercise regimens. Based on the provided evidences such protocols could result in (i) reduction of metabolic and cardiovascular risk factors primarily related to improved vascular function (NO bioavailability) in addition to positive muscular (up-regulation of muscle oxidative enzymes, ion transport proteins and muscle activation/perfusion) and (ii) neuro-vegetative adaptations.

\section{AUTHOR CONTRIBUTIONS}

All authors listed, have made substantial, direct and intellectual contribution to the work, and approved it for publication.

cardiovascular performance in healthy elderly: a review of the literature. Am. J. Geriatr. Cardiol. 7, 25-32.

Coté, T. R., Stroup, D. F., Dwyer, D. M., Horan, J. M., and Peterson, D. E. (1993). Chronic obstructive pulmonary disease mortality. A role for altitude. Chest 103, 1194-1197.

Degache, F., Larghi, G., Faiss, R., Deriaz, O., and Millet, G. (2012). Hypobaric versus normobaric hypoxia: same effects on postural stability? High Alt. Med. Biol. 13, 40-45. doi: 10.1089/ham.2011.1042

Faeh, D., Gutzwiller, F., Bopp, M., and Swiss National Cohort Study Group (2009). Lower mortality from coronary heart disease and stroke at higher altitudes in Switzerland. Circulation 120, 495-501. doi: 10.1161/CIRCULATIONAHA.108.819250

Faeh, D., Moser, A., Panczak, R., Bopp, M., Röösli, M., Spoerri, A., et al. (2016). Independent at heart: persistent association of altitude with ischaemic heart disease mortality after consideration of climate, topography and built environment. J. Epidemiol. Community Health. doi: 10.1136/jech-2015-206210. [Epub ahead of print].

Faiss, R., Girard, O., and Millet, G. P. (2013). Advancing hypoxic training in team sports: from intermittent hypoxic training to repeated sprint training in hypoxia. Br. J. Sports Med. 47(Suppl. 1), i45-i50. doi: 10.1136/bjsports-2013092741

Gallagher, D., Ruts, E., Visser, M., Heshka, S., Baumgartner, R. N., Wang, J., et al. (2000). Weight stability masks sarcopenia in elderly men and women. Am. J. Physiol. Endocrinol. Metab. 279, E366-E375.

Haider, T., Casucci, G., Linser, T., Faulhaber, M., Gatterer, H., Ott, G., et al. (2009). Interval hypoxic training improves autonomic cardiovascular and respiratory control in patients with mild chronic obstructive pulmonary disease. J. Hypertens. 27, 1648-1654. doi: 10.1097/HJH.0b013e32832 c0018

Haufe, S., Wiesner, S., Engeli, S., Luft, F. C., and Jordan, J. (2008). Influences of normobaric hypoxia training on metabolic risk markers in human 
subjects. Med. Sci. Sports Exerc. 40, 1939-1944. doi: 10.1249/MSS.0b013e31817 f1988

Hoppeler, H., Klossner, S., and Vogt, M. (2008). Training in hypoxia and its effects on skeletal muscle tissue. Scand. J. Med. Sci. Sports 18(Suppl. 1), 38-49. doi: 10.1111/j.1600-0838.2008.00831.x

Janssen, I., Heymsfield, S. B., and Ross, R. (2002). Low relative skeletal muscle mass (sarcopenia) in older persons is associated with functional impairment and physical disability. J. Am. Geriatr. Soc. 50, 889-896.

Kayser, B., and Verges, S. (2013). Hypoxia, energy balance and obesity: from pathophysiological mechanisms to new treatment strategies. Obes. Rev. 14, 579-592. doi: 10.1111/obr.12034

Kon, M., Ohiwa, N., Honda, A., Matsubayashi, T., Ikeda, T., Akimoto, T., et al. (2014). Effects of systemic hypoxia on human muscular adaptations to resistance exercise training. Physiol. Rep. 2:e12033. doi: 10.14814/phy2.12033

Kujaník, S., Snincák, M., Vokál, J., Podracký, J., and Koval, J. (2000). Periodicity of arrhythmias in healthy elderly men at the moderate altitude. Physiol. Res. 49, 285-287.

Lenaz, G., Bovina, C., D’Aurelio, M., Fato, R., Formiggini, G., Genova, M. L., et al. (2002). Role of mitochondria in oxidative stress and aging. Ann. N. Y. Acad. Sci. 959, 199-213.

Leuenberger, U. A., Gray, K., and Herr, M. D. (1999). Adenosine contributes to hypoxia-induced forearm vasodilation in humans. J. Appl. Physiol. 87, 2218-2224.

Leuenberger, U. A., Johnson, D., Loomis, J., Gray, K. S., and MacLean, D. A. (2008). Venous but not skeletal muscle interstitial nitric oxide is increased during hypobaric hypoxia. Eur. J. Appl. Physiol. 102, 457-461. doi: 10.1007/s00421007-0601-x

Levine, B. D., Zuckerman, J. H., and deFilippi, C. R. (1997). Effect of high-altitude exposure in the elderly: the Tenth Mountain Division study. Circulation 96, 1224-1232.

Levy, D., Larson, M. G., Vasan, R. S., Kannel, W. B., and Ho, K. K. (1996). The progression from hypertension to congestive heart failure. JAMA 275, 1557-1562.

Lundby, C., Calbet, J. A., and Robach, P. (2009). The response of human skeletal muscle tissue to hypoxia. Cell Mol. Life Sci. 66, 3615-3623. doi: 10.1007/s00018009-0146-8

Messina, E. J., Sun, D., Koller, A., Wolin, M. S., and Kaley, G. (1992). Role of endothelium-derived prostaglandins in hypoxia-elicited arteriolar dilation in rat skeletal muscle. Circ. Res. 71, 790-796.

Millet, G. P., Roels, B., Schmitt, L., Woorons, X., and Richalet, J. P. (2010). Combining hypoxic methods for peak performance. Sports Med. 40, 1-25. doi: 10.2165/11317920-000000000-00000

Morishima, T., Kurihara, T., Hamaoka, T., and Goto, K. (2014). Whole body, regional fat accumulation, and appetite-related hormonal response after hypoxic training. Clin. Physiol. Funct. Imaging 34, 90-97. doi: 10.1111/cpf.12069

Mortimer, E. A. Jr., Monson, R. R., and MacMahon, B. (1977). Reduction in mortality from coronary heart disease in men residing at high altitude. N. Engl. J. Med. 296, 581-585.

Nespoulet, H., Wuyam, B., Tamisier, R., Saunier, C., Monneret, D., Remy, J., et al. (2012). Altitude illness is related to low hypoxic chemoresponse and low oxygenation during sleep. Eur. Respir. J. 40, 673-680. doi: 10.1183/09031936.00073111

Nishiwaki, M., Kawakami, R., Saito, K., Tamaki, H., Takekura, H., and Ogita, F. (2011). Vascular adaptations to hypobaric hypoxic training in postmenopausal women. J. Physiol. Sci. 61, 83-91. doi: 10.1007/s12576-010-0126-7

Perez-Padilla, R., and Franco-Marina, F. (2004). The impact of altitude on mortality from tuberculosis and pneumonia. Int. J. Tuberc Lung Dis. 8, 1315-1320.

Sasaki, H., Fukuda, S., Otani, H., Zhu, L., Yamaura, G., Engelman, R. M., et al. (2002). Hypoxic preconditioning triggers myocardial angiogenesis: a novel approach to enhance contractile functional reserve in rat with myocardial infarction. J. Mol. Cell Cardiol. 34, 335-348. doi: 10.1006/jmcc.2001.1516

Serebrovskaya, T. V., Manukhina, E. B., Smith, M. L., Downey, H. F., and Mallet, R. T. (2008). Intermittent hypoxia: cause of or therapy for systemic hypertension? Exp. Biol. Med. (Maywood) 233, 627-650. doi: 10.3181/0710-MR-267

Shapiro, B. B., Streja, E., Rhee, C. M., Molnar, M. Z., Kheifets, L., Kovesdy, C. P., et al. (2014). Revisiting the association between altitude and mortality in dialysis patients. Hemodial. Int. 18, 374-383. doi: 10.1111/hdi.12129
Sharma, G., and Goodwin, J. (2006). Effect of aging on respiratory system physiology and immunology. Clin. Interv. Aging 1, 253-260. doi: 10.2147/ciia.2006.1.3.253

Shatilo, V. B., Korkushko, O. V., Ischuk, V. A., Downey, H. F., and Serebrovskaya, T. V. (2008). Effects of intermittent hypoxia training on exercise performance, hemodynamics, and ventilation in healthy senior men. High Alt. Med. Biol. 9, 43-52. doi: 10.1089/ham.2008.1053.

Shi, B., Watanabe, T., Shin, S., Yabumoto, T., Takemura, M., and Matsuoka, T. (2014). Effect of hypoxic training on inflammatory and metabolic risk factors: a crossover study in healthy subjects. Physiol. Rep. 2:e00198. doi: $10.1002 /$ phy 2.198

Urdampilleta, A., González-Muniesa, P., Portillo, M. P., and Martínez, J. A. (2012). Usefulness of combining intermittent hypoxia and physical exercise in the treatment of obesity. J. Physiol. Biochem. 68, 289-304. doi: 10.1007/s13105-0110115-1

Valencia-Flores, M., Rebollar, V., Santiago, V., Orea, A., Rodríguez, C., Resendiz, M., et al. (2004). Prevalence of pulmonary hypertension and its association with respiratory disturbances in obese patients living at moderately high altitude. Int. J. Obes. Relat. Metab. Disord. 28, 1174-1180. doi: 10.1038/sj.ijo.0802726

Vedam, H., Phillips, C. L., Wang, D., Barnes, D. J., Hedner, J. A., Unger, G., et al. (2009). Short-term hypoxia reduces arterial stiffness in healthy men. Eur. J. Appl. Physiol. 105, 19-25. doi: 10.1007/s00421-008-0868-6

Verdijk, L. B., Koopman, R., Schaart, G., Meijer, K., Savelberg, H. H., and van Loon, L. J. (2007). Satellite cell content is specifically reduced in type II skeletal muscle fibers in the elderly. Am. J. Physiol. Endocrinol. Metab. 292, E151-E157. doi: 10.1152/ajpendo.00278.2006

Voss, J. D., Allison, D. B., Webber, B. J., Otto, J. L., and Clark, L. L. (2014). Lower obesity rate during residence at high altitude among a military population with frequent migration: a quasi experimental model for investigating spatial causation. PLoS ONE 9:e93493. doi: 10.1371/journal.pone.0093493

Wang, J. S., Chen, L. Y., Fu, L. L., Chen, M. L., and Wong, M. K. (2007). Effects of moderate and severe intermittent hypoxia on vascular endothelial function and haemodynamic control in sedentary men. Eur. J. Appl. Physiol. 100, 127-135. doi: 10.1007/s00421-007-0409-8

Wang, J. S., Wu, M. H., Mao, T. Y., Fu, T. C., and Hsu, C. C. (2010). Effects of normoxic and hypoxic exercise regimens on cardiac, muscular, and cerebral hemodynamics suppressed by severe hypoxia in humans. J. Appl. Physiol. 109, 219-229. doi: 10.1152/japplphysiol.00138.2010

Weil, B. R., Stauffer, B. L., Mestek, M. L., and DeSouza, C. A. (2011). Influence of abdominal obesity on vascular endothelial function in overweight/obese adult men. Obesity (Silver Spring) 19, 1742-1746. doi: 10.1038/oby.2011.189

Wiesner, S., Haufe, S., Engeli, S., Mutschler, H., Haas, U., Luft, F. C., et al. (2010). Influences of normobaric hypoxia training on physical fitness and metabolic risk markers in overweight to obese subjects. Obesity (Silver Spring) 18, 116-120. doi: 10.1038/oby.2009.193

Williams, M. A., Fleg, J. L., Ades, P. A., Chaitman, B. R., Miller, N. H., Mohiuddin, S. M., et al. (2002). Secondary prevention of coronary heart disease in the elderly (with emphasis on patients $>$ or $=75$ years of age): an American Heart Association scientific statement from the Council on Clinical Cardiology Subcommittee on Exercise, Cardiac Rehabilitation, and Prevention. Circulation 105, 1735-1743.

Winkelmayer, W. C., Liu, J., and Brookhart, M. A. (2009). Altitude and all-cause mortality in incident dialysis patients. JAMA 301, 508-512. doi: 10.1001/jama.2009.84

Yingzhong, Y., Droma, Y., Rili, G., and Kubo, K. (2006). Regulation of body weight by leptin, with special reference to hypoxia-induced regulation. Intern. Med. 45, 941-946. doi: 10.2169/internalmedicine.45.1733

Conflict of Interest Statement: The authors declare that the research was conducted in the absence of any commercial or financial relationships that could be construed as a potential conflict of interest.

Copyright (C) 2016 Millet, Debevec, Brocherie, Malatesta and Girard. This is an openaccess article distributed under the terms of the Creative Commons Attribution License (CC BY). The use, distribution or reproduction in other forums is permitted, provided the original author(s) or licensor are credited and that the original publication in this journal is cited, in accordance with accepted academic practice. No use, distribution or reproduction is permitted which does not comply with these terms. 